\title{
ANALYSIS ON THE ORTHOGRAPHIC ERRORS MARIED BY THE NATIVE ENGLISH LEARNERS OF SINHALA
}

\author{
Lokeshwari S. Karunarathna ${ }^{1}$
}

\begin{abstract}
The purpose of this research is to study the orthographical errors made by the native English second language (L2) learners of Sinhala. A blend of similarities and dissimilarities are visible between the orthography of English and Sinhala. Even though both languages are written horizontally in left to write direction, they do not share any scripts (letters) in common such as in English and French or English and Spanish. Sinhala has an alpha-syllabary written system, whereas English has an alphabetic written system. Due to the transfer effect (the influences from the first language (L1) on learning a second language (L2)) the native English students, who were learning communicative Sinhala, tended to mark errors in orthography in and outside the classroom. I have used the three most related theories for this study: The Transfer Theory, the Error Analysis and the Contrastive Analysis Hypothesis. This paper discusses five major categories in which the second language students of beginner level have made errors while practicing their Sinhala orthography. The data was collected from 35 students over a period of 5 years and has been analyzed using qualitative methods. The qualitative data analysis revealed seven major categories of errors commonly done by the second language students of beginner level while practicing their Sinhala orthography.
\end{abstract}

Keywords: Orthography, Sinhala, linguistic errors, second language
${ }^{1}$ Department of Sinhala, University of Ruhuna-Sri Lanka lokeshsk28@gmail.com

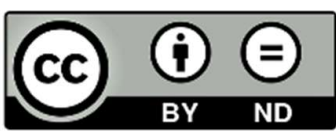

This article is published under the Creative Commons CC-BY-ND License (https://creativecommons.org/licenses/by-nd/4.0/). This license permits use, distribution and reproduction, commercial and non-commercial, provided that the original work is properly cited and is not change anyway. 


\section{INTRODUCTION}

Acquiring a language (mainly the first language) is considered as a prime achievement of a human infant. Language acquisition is a live process that occurs in the human brain. This process is a result of the interaction of cognitive abilities, physical abilities and social interactions. Broca's area and Wernicke's area in the brain along with the articulatory system represent the physical contribution towards the process of speech and communication. The cognitive ability in acquiring a language is inherent to humans. Yet the social interaction decides which language the infant would grasp and use and also the level of thoroughness, up to which the child would develop the knowledge in the language. Even though humans cannot make speech sounds at their birth, yet they reach a level of perfect communication in a language within a few years, passing through several stages. In other words, certain sections in human brain are open to welcome any human language at the onset of the infant's life. That language becomes the first language of the particular child. The child could gain proficiency in more than one first language, if the social atmosphere provides him with the access to multi language environment.

The first language plays a major role in the acquisition of a second language. The rules of the first language, which have already structured the cognitive linguistic capacity in the brain, always influence the acquisition of a second language. Any two human languages may demonstrate similarities as well as dissimilarities. Therefore, an effort on learning a new language, or a different set of linguistic rules and structures of a second language, may not offer the same experience for a student who has already acquired and built up the cognitive structures in the brain according to the first language.

The dominating power and the positive and negative influences of the first language over the second language have been examined by various linguists with different perspectives. During the last six decades second language learning has become a prominent research area in Applied Linguistics. The present study employs the Transfer Theory, Error Analysis and the Contrastive Analysis Hypothesis to cover the theoretical background.

Sinhala is a language with diglossia as its spoken and written forms show differences in vocabulary and grammar. The need of all the participants of this study was to learn the communicative spoken variety in Sinhala. Therefore, a majority of what they had documented on their worksheets were expressions of their speech.

\section{THEORETICAL}

\section{BACKGROUND}

At the earlier stage, the theory of error analysis was mainly employed in the field of education. Later the researchers in the linguistics field determined this as a useful theory to diagnose the areas which the students show higher tendencies to make errors during their second language learning process. Pitt Corder (1967) was a leading character in applying the error analysis to Applied Linguistics. 
Errors are commonly seen during any learning process, not only in language learning. In general, an error is simply identified as an "unwanted form" in the language, which the educators prefer to see avoided by their students. However, in applied linguistics errors are observed and treated in a different approach. According to Corder (1967) an error is an evidence of an ongoing learning process. In other words, errors indicate students' effort in expressing themselves with the current imperfect knowledge they have in a particular language. The errors occur while the students try to communicate in the target language. Therefore, errors reveal the sections in which the student might have issues in comprehension and need further clarifications by the instructor and more practice.

According to the transfer theory, any effort on learning something new is influenced by the previous knowledge on the related areas. Perkins and Salomon (1992) say,

"Transfer of learning the application of skills, knowledge, and/or attitude that were learning in one situation to another learning situation."

(http://www.nwlink.com/ donclark /hrd/learning/transfer.html)

This theory has a base on the education field but it was later connected with some other fields such as second language learning and language acquisition in Applied Linguistics. Explaining the concept of "language transfer" Gass and Selinker (2008) say,

"In general, what is meant is the use of prior linguistics information in a second language context" (Gass, 1988, p.385)

"More recently scholars such as Schachter (1983) have defined transfer in much broader terms incorporating all prior linguistic knowledge including the "imperfect" knowledge a learner may have of the L2." (Gass, 1988, p.385)

The prior knowledge on the first language, which has already organized the cognitive program of language in the brain, influences the second language learning process. The transfer theory along with its positive and negative transfer concepts therefore discusses about the errors made by the students due to the similarities and the differences between the first language and the target language.

The Contrastive Analysis Hypothesis $(\mathrm{CAH})$ claims that, since the first language has a strong influence on learning a second language, linguists can examine the dissimilarities between the two languages in order to predict the error making tendencies of the students.

"Difficulty and ease in learning is determined respectively by differences and similarities between the two languages in contrast." (Gass \& Selinker, 2008, p.97)

$\mathrm{CAH}$ believes "that greater the differences, the more errors will occur." (Gass \& Selinker, 2008, p.97)

In summary, transfer theory claims that second language learning is influenced by the prior language knowledge in the brain 
and $\mathrm{CAH}$ states, that considering the similarities and dissimilarities between the L1 and TL, predictions could be made about the errors of the students while the error analysis takes a positive approach towards errors saying that they exhibit the sections which need additional explanations and practice. Also this theory analyses the categorization and the avoiding strategies of the linguistic errors made by the second language students. Since the present study focuses on the orthographic errors made by native English students who were learning Sinhala as a second language, the ideas of these three theories directly relate with the scope of the present study.

\section{METHODOLOGY OF THE}

\section{STUDY}

This study mainly employed the qualitative methods and they were used to identify the different categories of orthographical errors. The main research problem of this study was "how the orthographical errors marked by the native English second language learners of Sinhala could be analyzed?" With the objective of examining the answer for the above research question, data was collected from thirty five subjects. They were between a range of 18 to 32 years. The range of their education background was in an array from undergraduate level to doctoral candidate level. Majority were students from four batches of ISLE - Bowdoin (Intercollegiate Sri Lanka Education) program.
Mainly two types of research instruments were collaboratively used for the data collection: teaching instrument and the test instrument. The teaching instrument was a set of handouts and worksheets created by the researcher. They were related to each lesson employed in the classroom. Some worksheets guided the students to do their homework while revising the lessons being taught in the class room. The answer sheets of the students were the test instrument. Apart from that, the diaries written by the students in Sinhala and notebooks of three students also contributed a considerable amount of data. Samples of the relevant illustrations of these students' worksheets are scanned and presented as figure 1-36 in the analysis section of this paper.

At the onset stage of the beginner's course, phonetic symbols were used to keep notes in vocabulary studies and express the ideas in Sinhala sentences. The symbols were not purely from the IPA (International Phonetic Alphabet) but rather a simplified version of that (see table 01). Since the students represented various academic fields but not linguistics, hence using a simplified version of symbols for transcription was more practical, effective and efficient. In this way, the students could express the simple ideas with a set of written symbols which are more familiar to them. This seemed to minimize the stress level of the adult second language learners of Sinhala at the beginning of the course. 
Figure 01: Using a simplified version of symbols for transcription - First day homework

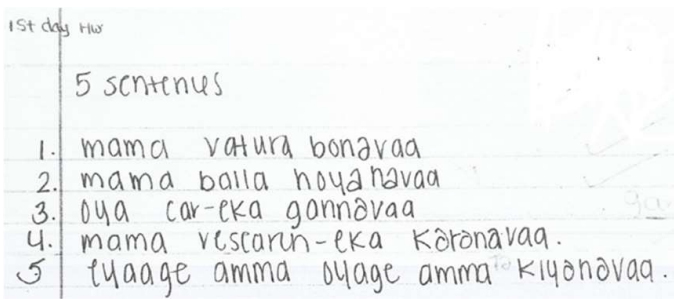

All the students of this course have been provided with a study guide for script practice prior to leaving the USA. Some of the students have done a self-study on this material. Before starting the formal instructions on script practice in the classroom, the students were asked to write the letters they could remember if they have self-learned. Errors found in this first worksheet have been presented in the analysis section.

In the next stage, Sinhala scripts were introduced in each lesson parallel to vocabulary and grammar. Experimenting the instructing of scripts to the L2 learners, the researcher had divided the letters into seven groups in a way that the students feel easier to identify the similarities and uniqueness of each letter compared to the letters which have somewhat similar

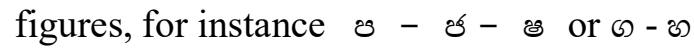
-

Table 01: Categories of scripts introduced to the beginners of Sinhala

\begin{tabular}{|c|c|c|c|c|c|c|c|c|}
\hline \multirow[t]{2}{*}{ Lesson } & \multicolumn{8}{|c|}{ Introduced Scripts and their simplified version of transcription } \\
\hline & \multicolumn{4}{|c|}{ Vowels } & \multicolumn{4}{|c|}{ Consonants } \\
\hline 01 & ¿ $\mathrm{a}$ & §o aa & $\varlimsup_{\varkappa} æ$ & ףॄææ & $\sigma \mathrm{ra} / \mathrm{r} \partial$ & อ Ta/Tə & e la/ & \\
\hline 02 & ๑ $\mathrm{i}$ & \%ั ii & $\mathrm{cu}$ & ¿ø uu & o ta/tə & ه ka/kə & ๑ na/nə & द da/də \\
\hline 03 & $\vartheta \mathrm{e}$ & of ee & $\odot e^{\circ}$ & & อ va/wa & อ ca/cə & & $\mathrm{Da} / \mathrm{D} ə$ \\
\hline 04 & ๑ 0 & (9) 00 & & & (อ) $\mathrm{ma} / \mathrm{m} ə$ & ค $\mathrm{ba} / \mathrm{b} ə$ & & \\
\hline 05 & «a iru & & & ¿̧аa iruu & $\begin{array}{l}\text { थs } \mathrm{sa} / \mathrm{s} \partial \\
\approx 0 \mathrm{Na} / \mathrm{Na}\end{array}$ & $\begin{array}{l}\omega \mathrm{ya} / \mathrm{y} ə \\
\circledast \mathrm{La} / \mathrm{L} \partial\end{array}$ & of & \\
\hline 06 & & & & & $\begin{array}{l}\text { ও pa/pə } \\
\text { ऽ ga/ gə }\end{array}$ & $\begin{array}{l}\text { ๘ ja/jə } \\
\text { ๘ ha/hə }\end{array}$ & GO & 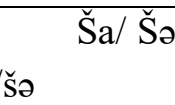 \\
\hline 07 & & & & & $\begin{array}{l}\text { es ňga/ ňg } \\
\text { \& } \quad \text { n̆da/ ̌n }\end{array}$ & $\begin{array}{r}\text { nója/ ňj } \\
0 \quad \text { mba/ }\end{array}$ & $\begin{array}{l}\text { m } \\
\text { mba/ }\end{array}$ & $\begin{array}{l}\mathrm{n} \mathrm{Da} / \mathrm{n} \mathrm{D} ə \\
\mathrm{c}^{\circ} \eta\end{array}$ \\
\hline
\end{tabular}

The logic behind the above categorization lies on the shape of the letters. Even though each letter has a scientific placement in the Sinhala alphabet, pedagogical language teaching (for native or non-native speakers of Sinhala) does not always stick to that order (grade 01 Sinhala book in government syllabus). It is visible that different teaching courses of Sinhala have different order of introducing the letters to the non-native speakers. (MacDougall, De Abrew 1979, Fairbanks, Gair, De Silva, 1981, Perera, 2007, McGarry, Liyanage, 2011) Since the order of introducing the Sinhala letters to second language learners and the different logics behind those 
methods could be identified as another area to be studied, we do not wish to go for a indepth description to state the logic behind the method used in the present study.

Following learning and practicing each script category, the students were provided with worksheets to transcribe short words that consist with the letters they already know. As diacritics were not introduced by this stage of the course, these words had only two to four letters without any diacritics. For example:

- Exercise on Transcribing to Sinhala -

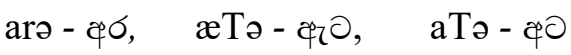

- Exercise on Transcribing to English symbols -

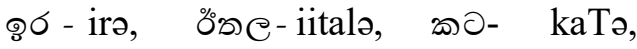

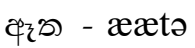

At the next stage of script practice the students were taught the diacritics. By that time they have collected a considerable number of vocabulary and sentence structures and gained basic knowledge in communicative Sinhala. Therefore, they were capable of writing the short sentences using Sinhala scripts. The data employed in this particular study was collected at this stage too.

\section{ORTHOGRAPHY IN SINHALA}

\section{AND ENGLISH}

The Oxford dictionary defines the term 'orthography' as "the conventional spelling system of a language."

(https://en.oxforddictionaries.com/definitio n/orthography)
According to Coulmas "orthography is the set of rules for using a script in a particular language i.e. the English orthography for Roman alphabet like symbol-sound correspondences, capitalization, hyphenation, punctuation, and so on." (Coulmas 2003)

Merriam-Webster's collegiate dictionary illustrate the term as,

" $1 \mathbf{a}$ : the art of writing words with the proper letters according to standard usage ex: the rules of English orthography

b : the representation of the sounds of a language by written or printed symbols" (MarriamWebster Dictionary, 1995, 821)

The same definition above touches an academic approach as

" 2 : a part of language study that deals with letters and spelling: ex a student of orthography is likely to be a good speller." (Marriam-Webster Dictionary, 1995, 821)

This is supported by the idea given in Oxford dictionary as

"...the study of spelling and how letters combine to represent sounds and form words."

(https://en.oxforddictionaries.com/definitio $\mathrm{n}$ /orthography)

Therefore, orthography is not only a convention of a speech community about the writing system of their language but also a field of study about the writing system/s of language/s. 


\section{Original Article}

(C) Author(s) September 2018

ISSN: 2279-3933

Sinhala has an alpha-syllabary writing system, where the consonant stands alone without any vowel sounds, but can be changed by adding vowel diacritics. Table 2 below illustrates how such a system works.

Table 2: The Sinhala Alpha-Syllabary System-Example with [k]- a $\overbrace{}^{\circ}$

\begin{tabular}{|c|c|c|c|c|c|}
\hline Pure & Short & Short & Pure & Long Vowel & Long \\
\hline Consonant & Vowel & Consonant & Consonant & & Consonant \\
\hline \multicolumn{6}{|l|}{ [k] } \\
\hline [k] 2$)^{p+}$ & [a] $\mathrm{q}^{\mathrm{q}}=$ & [ka] & [k] $28+$ & [aa] $\varnothing^{\jmath}=$ & [kaa] ฉు \\
\hline [k] $2 \mathbf{D}^{p+}$ & 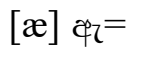 & [kæ] $2 /$ & [k] $28+$ & [ææ] $\varlimsup_{\xi}=$ & [kææ] ஐூ \\
\hline [k] $2 \operatorname{sp}^{p}$ & [i] $8=$ & [ki] & [k] $28+$ & [ii] $\%=$ & [kii] is \\
\hline [k] $2 \operatorname{s}^{p+}$ & {$[\mathrm{u}] \mathrm{C}=$} & {$[\mathrm{ku}] \mathfrak{D}^{2}$} & [k] $\sin ^{p}$ & [uu] $\mathrm{C}^{\varphi}=$ & [kuu] వ్ \\
\hline [k] $2 \operatorname{sp}^{p}$ & {$[\mathrm{e}] \hat{\vartheta}=$} & [kee] ๑றి & [k] $28+$ & [ee] $\approx=$ & [kee] ๑జి \\
\hline [k] 2$)^{p+}$ & [o] @ = & [koo] ๑ฉు & 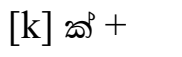 & [oo] @ = & [koo] ๑2 \\
\hline [k] 2$)^{p+}$ & [ai] $\oplus \vartheta=$ & [kai] ๑ఠவ & [k] $2 \sin ^{p}$ & [au] ஹø = & [kau] ๑ฉை \\
\hline
\end{tabular}

Diacritics are not only used to symbolize the vowel sounds, but sometimes instead of the consonants as well. For instance:

- Diacritic for $/ \mathrm{r} /$ - dha-r-mə ఎ৪ఠ - ఎతి (dharma)

- Diacritic for $/ \mathrm{r} /$ - kri-yaa อู่ิตง (actions)

- Diacritic for $/ y /$ - ga-dyə ऽદ્ટડ (prose)

Since Sinhala has a specific way of symbolizing any sound in the language, the beginner level second language learners and even the native kids feel comfortable on symbolizing the sounds of the words they know, at the onset of their orthography training. However, there are some situations where no difference is made in the pronunciation but have to use the correct spelling option in writing. The focus of our participants was not as advanced as that level. Therefore, even though the students were introduced the optional scripts for $/ \mathrm{Na} /$, (as $\sigma_{0}$ ) /La/ (as @) and /sha/ (as в/œ) sounds, they had freedom to use any of the two options in their own essay writing (except in the transcribing exercises).

English and Sinhala orthography does not share any symbols in common, whereas English do with French or Spanish. The systematic rules on employing the diacritics in Sinhala mark another crucial difference between the first and the second languages of these participants. English keeps the consonant and the vowels separately, but in reading the reader connects them as sound chunks or syllables whereas in Sinhala each 
syllable is conveyed as a unit which is interconnected with diacritics. For instance, in writing the word [Polonnaruwa], English keeps the consonants and the vowels separately but still the reader connects the appropriate sound units together while reading. In Sinhala /po//lo//n//na//ru//wa/

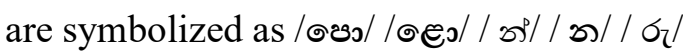
/ ¿/ but none of the vowels are visible separately instead as diacritics. These major differences between English and Sinhala orthography may cause error making tendencies due to the negative transfer effect arise in the L2 students.

\section{DATA ANALYSIS}

\section{ORTHOGRAPHIC ERRORS \\ MARKED BY THE SECOND LANGUAGE LEARNERS OF SINHALA}

\section{i. Errors due to misshapen scripts}

Compared to Sinhala, a native English learner of Spanish, German or French may feel much easier on learning the orthography as the alphabets of those languages share a considerable amount of similarities including the characters. However, every script in Sinhala alphabet is a novel character for native English second language learners. We must consider that memorizing and mastering on all of these new symbols in an intensive course environment is a challenge to a beginner. The dissimilarities between the first language and the target language cause difficulties to the students. Misshaping of the scripts is one of the most common error types found among the data. The example below exhibits an attempt on writing scripts for /i/ and /ii/ sounds.

Figure 02: Attempts on writing ๑, \%ั (/i/ and /ii/)

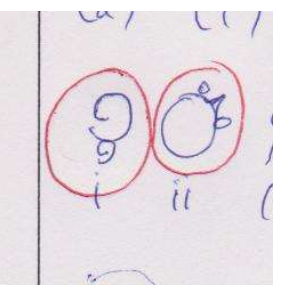

Figure 02 was an attempt taken when the student had self-learned and tried to memorize the shapes of the letters before the formal course was commenced. Since the student was not properly guided on how to direct the pencil from the starting point to the ending point of each letter, the student had tried to draw the symbol he saw on the book. Figure 03 illustrates another form of misshapen $/ \mathrm{i} /$.

Figure 03: An attempt on writing ๑ (i)

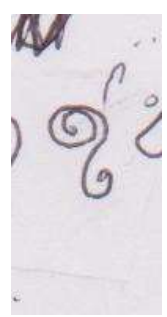
As mentioned in table 01, the letter for $/ \mathrm{Ta}$ / was introduced in the first lesson. The examples below illustrate the forms of misshapes the students had documented.

Figure 04: misshapen / O /

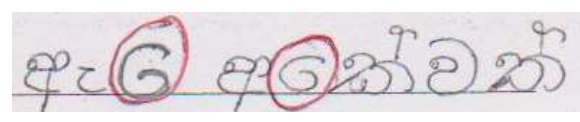

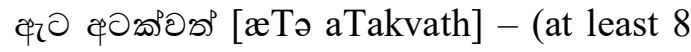
seeds)

Figure 05: ๑๐ - maTə (to me)

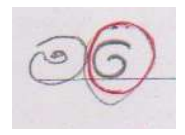


Figure 06: $\partial(\mathrm{T})$

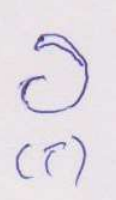

Figure 07: misshapen 0

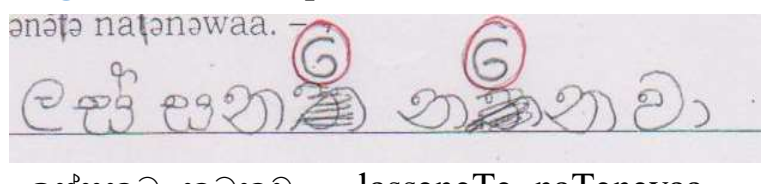

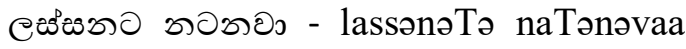
(dance beautifully)

Figuer 08: $\partial$ (Ta)

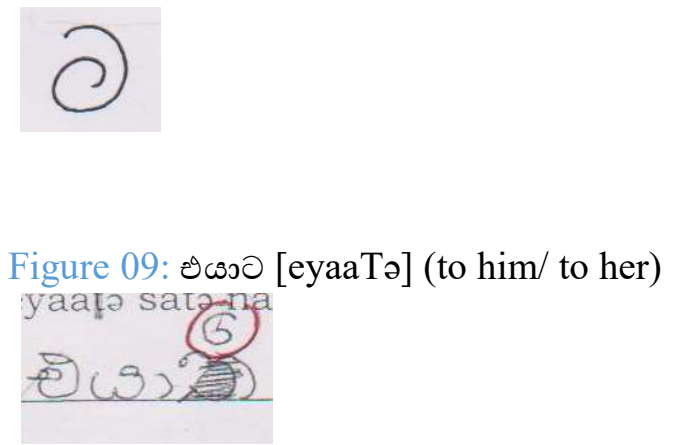

The misshapen /la/ script was found among the data which was a pre-teaching attempt of a student. The error has occured due to the misunderstanding about the starting point of the circular part.

Figure 10: misshapen e (la)

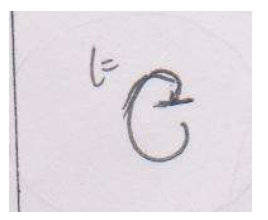

The figures 11-12 are another two selflearned attempts which the script for $/ \mathrm{da} /$ sound has got misshapen. In figure 11 it is conveyed that the student had taken an effort to memorize the script for $/ \mathrm{da} / / \mathrm{e} /$ with a comparison to script for $/ \mathrm{i} /$ ๑. Even though the facing of the two circular parts in his letter /ç/ show an accuracy, but the error has occurred due to the misshape of the head or the starting point of the letter.

\section{Figure 11: Misshapen द̨ (da)}
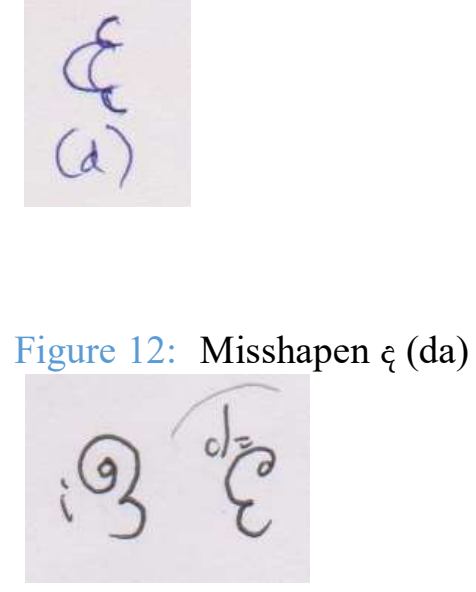

The self-study effort of this student is mentioned below, and it illustrates the confusion going on in the student's cognition or in memory about the pointing style of the relevant letter. After the instructions were given in lesson two, the student had perceived the uniqueness of each similar looking consonant scripts (/ka/, /ta/, /na/ - ฉ, ๖, ๖).

Figure 13: misshapen $\boldsymbol{\wp}$ (na)

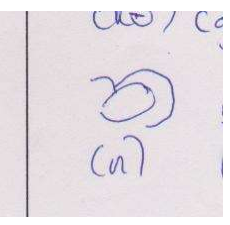




\section{Original Article}

Errors marked due to the misshaping of scripts for the $/ \mathrm{ya} /$ and $/ \mathrm{sa} /$ sounds are illustrated below. It has to be noted again that these errors are also found in worksheet one which tested the self-practiced scripts.

Figure 14: misshapen / $s$ / (ya)

\section{(i)}

The example below shows that an erroneous condition had occurred due to the absence of the little horizontal line heading to left side from the head of the letter and also due to the wrong level of finishing point. The letter is more likely to be identified as a misshape version of /sa/ but the student himself has mentioned the English transcription next to the Sinhala script as /Da/ ¿.

Figure 15: misshapen /®/ (Da)

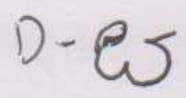

Addition of a nasal diacritic to /sa/ script has made the error regarding the example below.

Figure 16: misshapen /æs/ (sa)
The following example illustrates the misperception of the student on the shape of the vowel /o/ @ and nasal /mba/ @ scripts.

Figure 17: misshapen @ / mba/

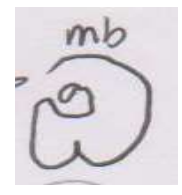

/ma/ was another misshapen script by the students. This error was marked at a quiz which was given even after the formal classroom instructions.

Figure 18: misshapen ๑ /ma/

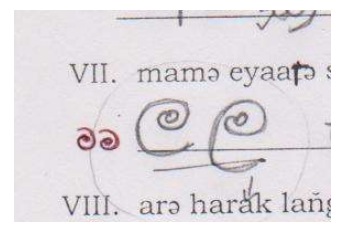

/pa/, /ja/, alveolar /sha/ (๖, ๖, ও) and /ga/, /ha/, palatal /sha/ (๑, ॐ), ๑) could be identified as two groups of scripts which exhibit similar shapes up to a certain extent. The examples below illustrate dropping of needy sections or adding of unwanted sections to the script which have led to errors. Misshapen /œ/ (sa) occurred by not adding the horizontal line to left is illustrated among the letters below.

Figure 19: misshapen /œ/ (sa)

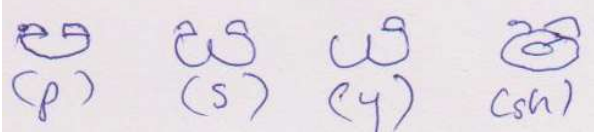

The error is visible by writing /pa/ with an unwanted line in the left side. 
Figure 20: misshapen /o/ (pa)

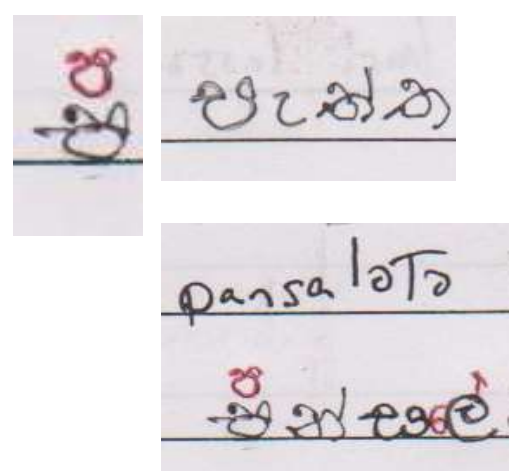

In the attempts below the ending point of /pa/ shows an incompletion.

Figure 21: misshapen / $/$ / (pa)

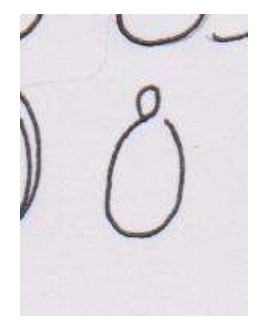

The script below is a mixture of /sa/, /ya/ or $/ \mathrm{fa} /(\omega, \omega$, o $)$.

Figure 22: A misshapen letter

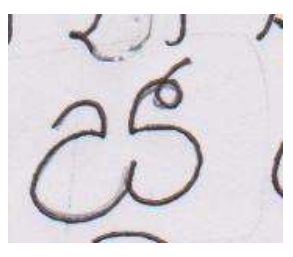

ii. Errors due to misperception of the sounds
Another very common orthographical error has been caused due to the perception difficulty on certain speech sounds in the target language. The students showed much difficulty in perceiving the difference between certain pairs of consonants such as $/ \mathrm{ta} / \mathrm{vs} / \mathrm{Ta} /$ and /da/ vs /Da/ (๖-O, ç-Ð). The perception difficulty has let the second language students making errors in writing the sounds they hear. In the examples below, the student's wrong writing is illustrated first and the correct orthography is given next with IPA transcription.

\section{- Using /ta/ instead of /Ta/}

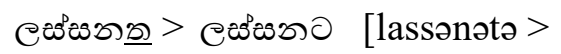

lassənəTə] beautifully

๓ฺฺอง> ๓อ๘อง [natənəvaa > naTənəvaa] dance

ecsos > enso [eyaatə > eyaaTə] to $\operatorname{him} /$ her

- Using /Ta/ instead of /ta/

ออุ > อฉุ [vaTurə > vaturə] water

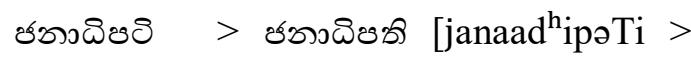
janaad ${ }^{\mathrm{h}}$ ipəti ] the president

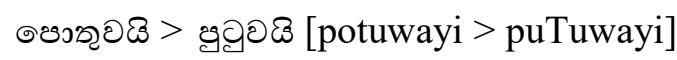
chair and

Figure 23: iiTalə > iitalə

\section{iitalə}

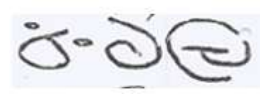

- Using /da/ instead of /Da/

๑งว६ > ๑ง๖ญి [podi> poDi] small

๑ตว 


\section{Original Article}

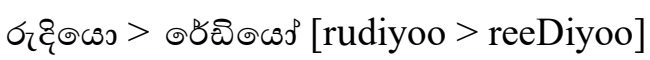
the radio

- Using /Da/ instead of /da/

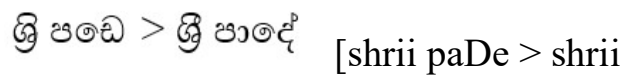
paadee] Sri pada

Figure 24: karəDərə > karədərə

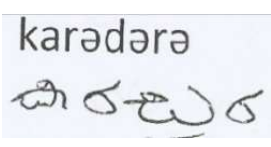

Figure 25: aaDərə > aadərə

aadəra va Фैग

\section{iiii. Errors in using diacritics}

Diacritics play a major role in alphasyllabic writing systems such as Sinhala. Similarities are visible between different definitions given for the term 'diacritic' as the Marriam- Webster's defines it as,

"a mark near or through an orthographic or phonetic character or combination of characters indicating a phonetic value different from that given the unmarked or otherwise marked element"

(https://www.merriamwebster.com/dictionary/diacritic)

Or as,

"an accent near or through an orthographic or phonetic character..." (merriam-webster, 1995, 318)

and the Oxford concise dictionary of Linguistics indicates as,

"Any mark in writing additional to a letter or other basic element: e.g. the tilde ( ) distinguishing $\tilde{n}$ from $n$ in Spanish; the umlaut (") distinguishing ä $\ddot{o} \ddot{u}$ from a o $\mathrm{u}$ in German, or, in phonetic transcription, to indicate that a vowel is centralized" (Matthews 2005, p.96)

Students had shown a tendency of using diacritics for long vowels where they should symbolize the sound with a short vowel.

- Writing the long vowel diacritic at unnecessary places

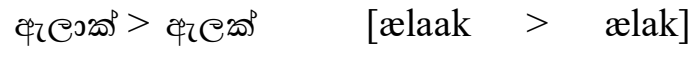
(canal)

ฉ boys's name)

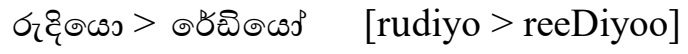
(radio)

According to the convention in Sinhala, several diacritics are used together to symbolize a particular sound. Some students had shown a tendency of making errors on diacritic combinations.

$$
\begin{aligned}
& \odot \mathcal{C}^{\mathrm{\omega} \omega S}>\odot \mathcal{C}^{\mathrm{઼} ఓ} \quad \text { [not pronounceable }> \\
& \text { leesiyi] (easy) }
\end{aligned}
$$

The figure below shows an error occurred due to the negligence of combining the diacritics. The student wanted to write the shorten form of the name of his friend 
(Joseph $>$ Joe) but has kept the script as /ja/ without adding the three needed diacritics.

Figure 26: Dropping the three diacritics needed for ๑ษో /joo/

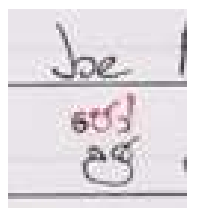

Sometimes, in representing pure consonant sounds (hal akuru), two different diacritics Table 03: Different patterns of paapili are used in the Sinhala orthographic system. For instance, hal kiriims is used

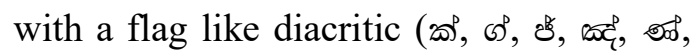

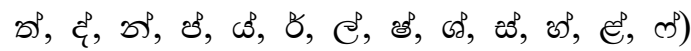
whereas the other diacritic (cap like diacritic) is used with another group of consonants (อి, ฮิ, ఐి, ఐి, ๑ి, ๑, ఠิ). Moreover, two different types of diacritics alone with an irregular pattern are used to symbolize the $/ \mathrm{u} /$ vowel sound. Since this diacritic is usually placed at the bottom of the script as shown in table 03, it is called paapilla, conveying 'the diacritic placed at the foot'.

\begin{tabular}{|c|c|c|}
\hline $\begin{array}{l}\text { Scripts with circular } \\
\text { shaped paapilla }\end{array}$ & $\begin{array}{l}\text { Scripts with square } \\
\text { type paapilla }\end{array}$ & $\begin{array}{l}\text { Irregular } \\
\text { patterns }\end{array}$ \\
\hline $\begin{array}{ll}D_{2} & / \mathrm{ku} / \\
D_{2} & / \mathrm{gu} / \\
D_{2} & / \mathrm{tu} /\end{array}$ & $\begin{array}{l}\text { gु /nu/ } \\
\text { g } / \mathrm{pu} / \\
\mathrm{g} / \mathrm{lu} / \\
\mathrm{g} / \mathrm{yu} / \\
\mathrm{g} / \mathrm{hu} / \\
\mathrm{g} / \mathrm{mu} /\end{array}$ & $\begin{array}{l}\text { द्g/du/ } \\
\sigma_{7} / \mathrm{ru} / \\
\sigma / \mathrm{Lu} /\end{array}$ \\
\hline
\end{tabular}

Memorizing these variations need an additional effort from students. The examples below illustrate the errors which have been occurred due to the use of the inappropriate diacritic. In the example above the error occurred due to the use of wrong hal kiriima diacritic with /D/ - / ๑ / and the $/ \mathrm{r} /-/ \sigma /$ scripts.

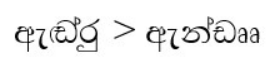

Not pronounceable $>$ ænDruu (Andrew)

The figure below illustrates an error occurred due to the wrong use of circular shaped paapillo with /ha/. The lightly visible erased line situated at the bottom of /ha/ conveys us that the student has previously used the correct form of diacritic but has later changed it to the wrong form. This is an evidence of confusion still going on in the student with regard to the use of diacritics. It also proves that the learning is happening at this stage.

Figure 27: Misuse of circular shaped paapilla 


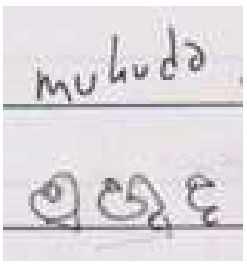

The error illustrated by the following figure conveys us that the student has identified each letter but still has confusion on mixing the consonants with vowel sounds. Moreover, the student is still not aware that in Sinhala, the vowel scripts are not written at the end of a word. Even though the vowel may be used in the middle position in a very limited number of Sinhala proper nouns such as Naaula, Beliatta, Gelioya, Galoya where the names are used as one unit, yet the student is still not aware that a vast majority of words in Sinhala do not consist of vowels in middle position of a word.

Figure 28: Error on mixing the consonant and vowel<smiles>[GeH3]</smiles>

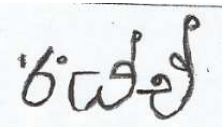

iv. Errors regarding the pre-nasal
scripts

There are five pre-nasal scripts in Sinhala alphabet. Four out of them show similarities (in appearance) with the four scripts for voiced, non-aspirated sounds /ga/, /ja/, /Da/ and /da/ (๖, ช, ఐ, द). To convey the pre-nasal quality, a pre-nasal diacritic is added to the left side of the

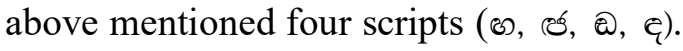
Only when /ba/ gets pre-nasalized, a different script is used instead of just adding the pre-nasal diacritic to the existing /ba/. This special script is somewhat similar to the vowel /o/ (๑) in shape but also highlights its identity with the circling shape placed at the bottom of the script (๑ vs @). Some students had shown confusion over these two scripts. The examples below show the attempts of self-studied students who have not identified the uniqueness of the nasal /ba/ character.

Figure 29: Errors on misidentification of ๑ - the nasal /mba/ script
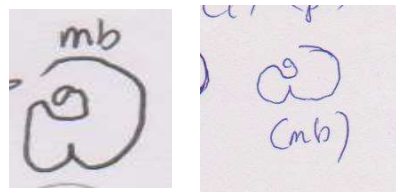

The other very common error in writing the pre-nasal letters occurred due to the way how the students combine the pre-nasal script with other scripts in a word.

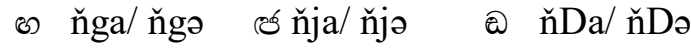

$$
\begin{aligned}
& \text { \& ňda/ n̆də @ m̌ba/m̌bə }
\end{aligned}
$$

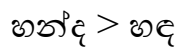

$$
\begin{aligned}
& \text { handə > haňdə (moon) }
\end{aligned}
$$

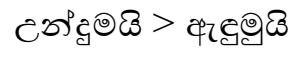

undumuyi $>$ æňdumuyi (cloths and)

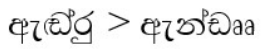

$$
\begin{aligned}
& \text { æňDru }>\text { æňDruu (Andrew) } \\
& \text { ๒கీడి > nangiyi } \\
& \text { naňgiyi > nangiyi (younger sister and) }
\end{aligned}
$$

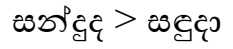

$$
\begin{aligned}
& \text { sanduda }>\text { saňdudaa }
\end{aligned}
$$


v. A correct orthographic

interpretation yet breaking of

\section{conventions}

Native English learners of Sinhala had a tendency of paying attention on the pronunciation of the word and trying to convert it to scripts. In that sense they were not wrong in writing the following words. The /au/ sound is represented with the diacritic called "gayanukiththa" ( ৩) which is normally used along with kombuwa $(\odot)$ in the consonants.

Figure 30: [Taumə > Tawumə]

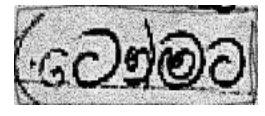

Figure 31: [raumə > rawumə]

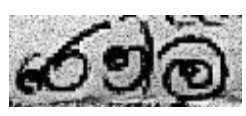

Therefore, writing/Taumə/ and /raumə/ with kombuwa along with gayanukiththa make sense in representing the pronunciation. However, according to the convention of the Sinhala speech community, those words are supposed to be written with the /wu/ script. [Tawumo]

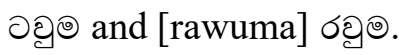

In the following example the student has made an error by using /o/ instead of $/ \mathrm{u} /$ at the onset position of the word. Apart from that, according to the convention, an error has occurred due to the writing of /dau/ as one script instead of two separate scripts as /dawu/.

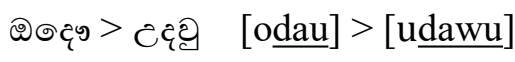

\section{vi. Errors occurred due to the inappropriate script}

Sometimes the students had marked errors by using an inappropriate script instead of the correct script.

อњб > อњ

[casərə] instead of [vasərə] - the year

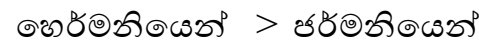

[herməniyen] instead of [jərməniyen] from Germany

ติษ ผุిิ

[gipə satiye] instead of [giyə satiye] - last week

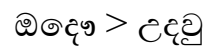

[odau] instead of [udawu] - help

The figures below illustrate the misperception in the student towards /va/ and /cha/ scripts.

Figure 32: Orthographic errors marked with /va/

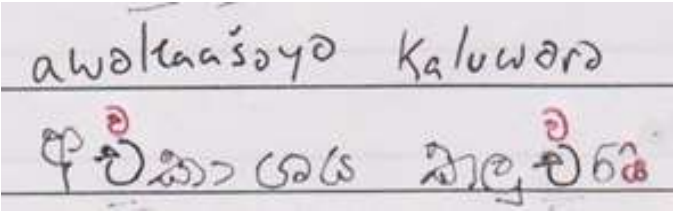

Figure 33: Orthographic errors marked with /va/ 
baeluwa.

D) 2020,0

Figure 34: Orthographic errors marked with /val

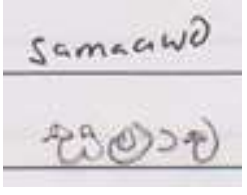

Figure 35: Writing the consonant /ca/ instead of vowel /e/

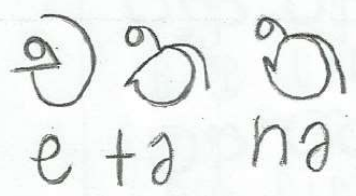

The examples above shows how the consonant /ca/ has misused instead of /e/ and /va/. The similarity in appearance must be the cause for this error.

\section{vii. Linguistic errors occurred due to the slips}

Some linguists (Catalan, 1997; Corder, 1981) have presented categorization criteria of linguistic errors. Among them, slips is one category with many subdivisions such as slips of the ears, slips of the eyes, slips of tongue and slips of the pen. Not only by a second language learner, but a slips could occur even with a native speaker. Language is mainly a cognitive process. Therefore, it is possible that a slip of the brain could cause an error in language use. Brain along with the neuro system plays a major role in the communication process. They have the control over each organ of the articulatory system. Slips may occur due to negligence, fatigue or internal or external disturbances.

Weaknesses and issues in hearing or mishearing may cause slips of ear and misreading causes slips of eyes. Even though the articulatory system of a person does not have any physical issue, yet consciously or unconsciously misspeaking could occur sometimes. In error analysis this is called slips of tongue. Slips of pen could occur by writing the inappropriate symbols or words, dropping of needy symbols or words, or by occurrence of grammatical errors due to the miswriting. Some of the errors revealed in this study too were the slips of pen as they were not continuously found but only found randomly.

Figure 36: Slip of a pen for /va/

\begin{tabular}{|c|c|}
\hline 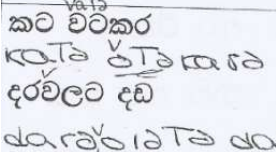 & $\begin{array}{l}\text { อలక అీమ } \\
\text { vacana }\end{array}$ \\
\hline
\end{tabular}

In the above figure 36, /va/ has been expected to be transcribed in three places in the given three words. The transcription of the script /va/ of the word [อวฉo] in the upper left corner has been misperceived as $/ \mathrm{o} /$. It is clearly seen that the letter /va/ in

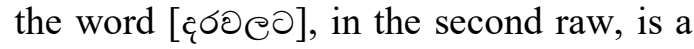
later addition which the student missed to write at his first attempt. The script /va/ in the word [ออ凸] has been transcribed correctly. Therefore, except in the first word the student has perceived the same letter printed in the same font and same size accurately. The repeated use of a wrong 
form of language is determined as a linguistic error. It illustrates an incomplete or an insufficiency of knowledge on a particular area of the language. The linguistic behavior of the above student conveys us that he or she has no issue on perceiving the letter $\partial$ but a slip of a pen or slip of the eye could have been occurred.

\section{CONCLUSIONS}

The main research question of this study focused on a qualitative analysis of the orthographical errors marked by the native English second language learners of Sinhala. Sinhala and English orthography illustrates similarities as well as several dissimilarities hence this condition creates a transfer effect for the second language students.

The error making tendencies could be predicted due to these documented differences. Seven categories of orthographic errors were identified with the data. They are 1) errors due to misshapen scripts, 2) errors due to misperception of the sounds 3 ) errors in using diacritics, 4) errors regarding the pre-nasal scripts, 5) a correct orthographic interpretation yet breaking of conventions, 6) errors occurred due to the inappropriate script, and 7) linguistic errors occurred due to the slips.

The subjects had marked errors in writing both the vowels and the consonants but majority of the orthographic errors were marked on the consonants. In this regard, we have to consider that the ratio between the number of vowels to pure consonants taught in this course is $16: 29$. In addition to this difference, the orthographic presentation of the vowels is standard while the orthographic presentation of some consonants may bear different formations. The above mentioned quantity difference in vowels and consonants gives an obvious reason for the possible difference in error reporting tendencies pertaining to vowels and consonants by the students. Higher number of the consonants may cause for the higher number of error reporting tendencies. It is highlighted that the majority of the orthographical errors on misshaping the letters have occurred in the case of self-learned students. However, this tendency of error marking has become settled down following formal class room instructions.

\section{Acknowledgements}

I thank Mr. Bandara Herath, the Cornell University, for putting me en-route in the discipline of second language teaching. Thanks are due to Prof. Liyanage Amarakeerthi, the University of Peradeniya, for his good guidance. I respectfully remember the names of Dr. Soo Jung Chan, Dr. Krassimira D. Charkova and Associate Professor Karen Baertsch in the Southern Illinois University, Corbondale - IL for the valuable research training they have given to me. I thank Dr. Darshani Gunathillake for her esteemed encouragement in my research work on error analysis in L2. A special thanks goes to my father and to my colleague Miss. Nethranjalee Dissanayake for the valuable comments. I would like to recall my mother and Asiri for their dearly patience towards me during this study and preparation of this paper.

\section{REFERENCES}


Catalan, R.J. (1997). Terms \& Definitions of Errors in SLA, Barcelona English Language and Literature Studies, 8,60-81. Corder, S.P. (1967). The Significance of Learners' Errors. International Review of Applied Linguistics in Language Teaching, 5, 161-170. Also found in http://dx.doi.org/10.1515/iral.1967.5.14.161

Corder, S.P. (1981). The significance of learner's errors. Oxford: Oxford University Press.

Coulmas, F. (2003). Writing systems: an introduction to their linguistic analysis. Cambridge: Cambridge University Press.

Fairbanks, G.H., Gair, J.W., De Silva, M.W.S., (1981). Zolloquial Sinhalese. South Asia Program, Cornell University, Ithaka, USA.

Gass, S.M. (1988). Second Language Acquisition and Linguistic Theory: The role of language transfer. Ed. Flynn, S. and O’Neil, W. Linguistic Theory in Second Language Acquisition. Kluwer Academic Publishers, London.

Gass, S.M., Selinker, L. (2008). Second Language Acquisition " Routledge Taylor \& Francis Group" New York and London. Karunarathna, L.S. (2014). Perception of Consonant Gemination by Native English Learners of Sinhala: The Effect of Training. M. A. Thesis. http://opensiuc.lib.siu.edu/theses/1445/

Karunarathna, L.S. (2016). A Practical Methodology to Teach Spoken Sinhala as a Second Language, Unpublished Thesis, University of Peradeniya.

MacDougall, B.G., De Abrew, Kamini (1979). Sinhala Basic Course Module 01-
Biginning signs and letters. Foreign service Institute, Department of State, Washington DC. Also finds in https://files.eric.ed.gov/fulltext/ED192569. pdf

Marriam-Webster's Collegiate Dictionary (10 ${ }^{\text {th }}$ Edition). (1995). Marriam-Webster, Incorporated, Springfield, Massachusetts, USA. Also found in https://www.merriamwebster.com/dictionary/orthography Matthews, P.H. (2005). The Concise Oxford Dictionary of Linguistics. Oxford University Press.

McGarry, T., Liyanage, A. (2011).

Beginning Colloquial Sinhala- An

Introductory Sinhala Curriculum. South

Asia Program, Cornell University, Ithaka, USA.

Perera, Shirley., (2007). Sinhala Katha Karamu (Let us speak Sinhala), Stamford Lake publication, Pannipitiya, Sri Lanka

Perkins, D.N., Salomon, G. (1992). Transfer of Learning. Contribution to the International Encyclopedia of Education, Second Edition. Oxford, England: Pergamon Press.

Richard, L. Venezky (2011). The Basis of English Orthography, Acta Linguistica Hafniensia, 10:2, 145-

159, DOI: $10.1080 / 03740463.1966 .10411$ 512

Schachter, J. (1983). A new account of language transfer. In $\mathrm{S}$. Gass and $\mathrm{L}$. Selinkar (Eds.) Language transfer in Language learning. (pp. 98-111). Rowley, MA: Newbury House. Also found in: https://scholarspace.manoa.hawaii.edu/bits tream/10125/38646/1/Schachter\%20(198

2)_WP1(1).pdf 
Journal of Social Sciences and Humanities Review (JSSHR)

Vol. 3, Issue 3 (156-174)

\section{Original Article}

(C) Author(s) September 2018

ISSN: 2279-3933

http://www.nwlink.com/ donclark/hrd/lear

https://www.merriam-webster.com

ning/transfer.html

Marriam-Webster Dictionary, 1995, 821

https://en.oxforddictionaries.com/definitio

www.nwlink.com

n/orthography 